\title{
Scanning Tunneling Microscope Investigation of Self-Assembled Rosette Nanotubes on Highly Ordered Pyrolytic Graphite
}

Jae-Young Cho, Gabor Borzsonyi and Hicham Fenniri

National Institute for Nanotechnology, National Research Council (NINT-NRC) and Department of Chemistry, University of Alberta, 11421 Saskatchewan Drive, Edmonton, Alberta T6G 2M9, Canada

The self-complementary $\mathrm{G} \wedge \mathrm{C}$ motif has been shown to undergo self-organization to form a sixmembered supramolecular rosette. These rosettes then stack to produce a well-defined tubular architecture (rosette nanotube, RNT) held together by H-bonds, $\pi-\pi$ stacking and hydrophobic effect (Fig. 1).

Although the structural aspects of self-assembled organic nanotubes have been extensively studied by atomic force microscopy (AFM), scanning electron microscopy (SEM), transmission electron microscopy (TEM), and scattering techniques (using neutrons, X-rays and light as a source of electromagnetic radiation), currently no scanning tunneling microscopy (STM) investigations were reported [1-3]. STM is the only tool that could reveal the details of the RNTs' supamolecular organization.

In this paper the molecular structure of RNTs deposited on highly ordered pyrolytic graphite (HOPG) was investigated using scanning tunneling microscopy (Fig. 2). Optimal sample and tip preparation, and STM conditions will be presented and an interpretation of the images obtained will be discussed [4].

References

[1] Ross S. Johnson, Takeshi Yamazaki, Andriy Kovalenko, and Hicham Fenniri, J. Am. Chem. Soc. 2007, 129, 5735-5743.

[2] Jesus G. Moralez, Jose Raez, Takeshi Yamazaki, R. Kishan Motkuri, Andriy Kovalenko, and Hicham Fenniri, J. Am. Chem. Soc. 2005, 127, 8307-8309.

[3] Hicham Fenniri, Bo-Liang Deng, and Alexander E. Ribbe, J. Am. Chem. Soc. 2002, 124, 11064-11072. 
[4] This research program was supported by the National Institute for Nanotechnology and the National Research Council CANADA.<smiles></smiles>

a

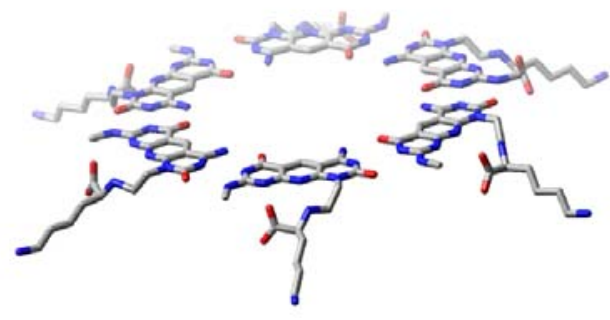

b

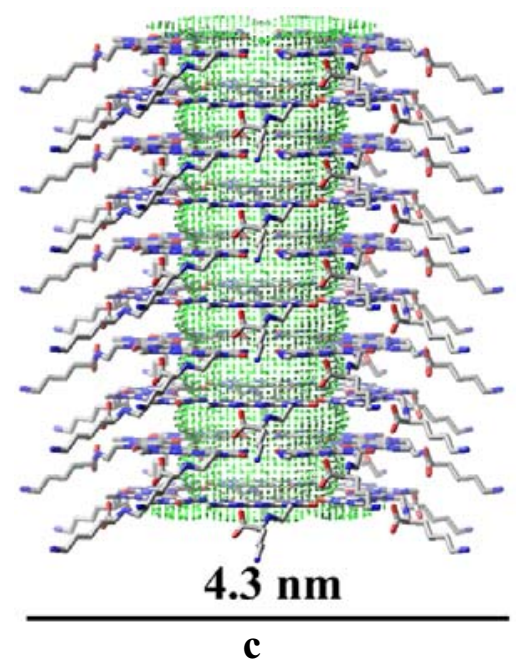

c

FIG. 1. Self-assembled rosette nanotubes (a) Tricylic $\mathrm{G} \wedge \mathrm{C}$ base (b) hexameric rosette (c) RNT
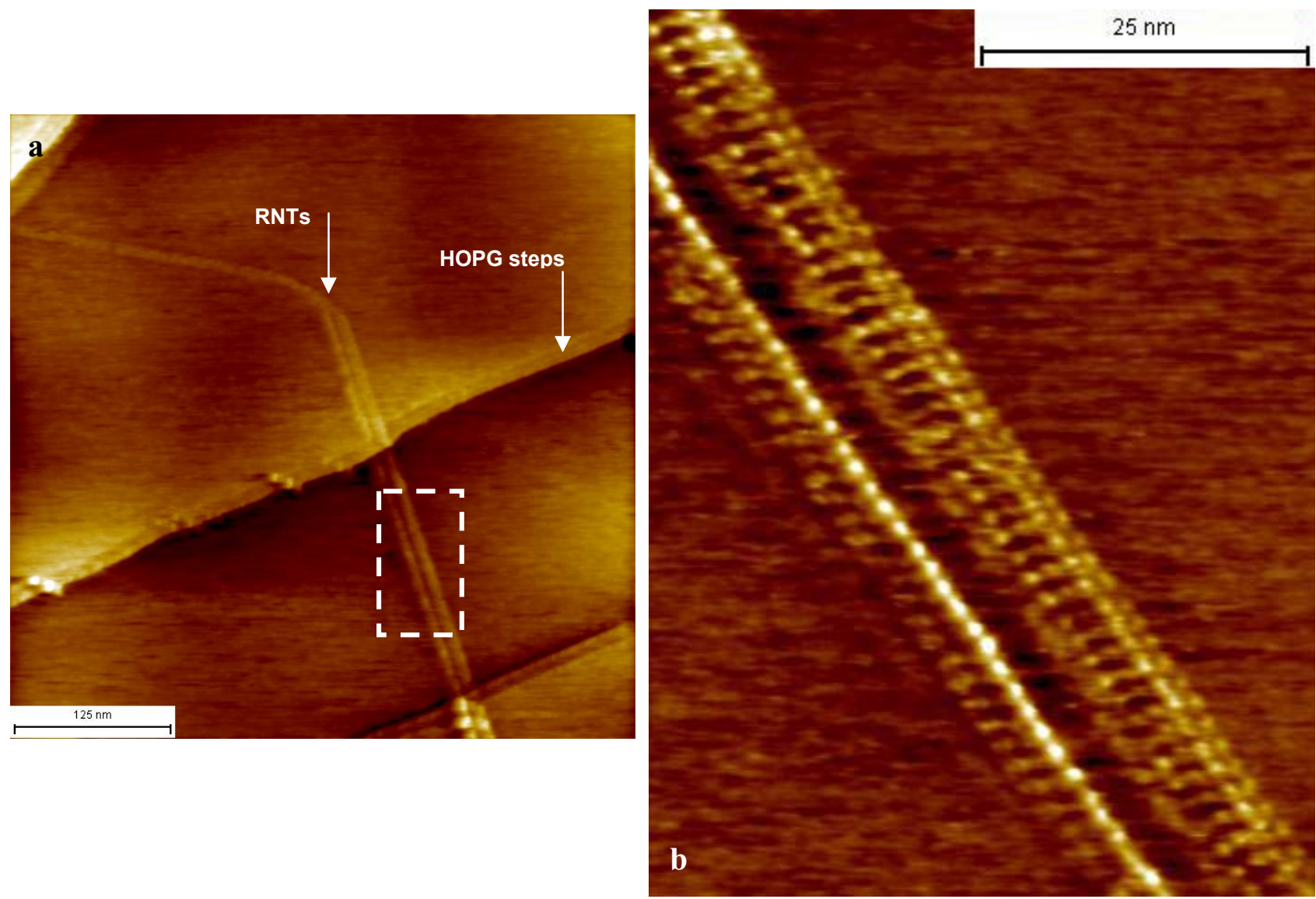

FIG. 2. STM images of self-assembled rosette nanotubes on HOPG (a) constant current mode (b) magnified image of dashed area in (a). 